\title{
PERCEPÇÕES SOCIOLINGUÍSTICAS, AVALIAÇÕES SUBJETIVAS E ATITUDES LINGUÍSTICAS: TRÊS DOMÍNIOS COMPLEMENTARES*
}

\section{Marcus Garcia de Sene**}

Resumo: Este artigo conjectura apresentar uma revisão de literatura e uma discussão teórica-metodológica de alguns estudos de percepções sociolinguísticas, avaliações subjetivas e atitudes linguísticas. Para isso, toma-se como pressupostos os trabalhos de Preston (1986), Gibson (1991), Campbell-Kibler (2006), Podesva (2007), Levon (2007), Eckert (2012), Oushiro (2015), Weinreich, Labov e Herzog (1968), Labov (2010), Lambert et al. (1960), Oppenheim (1966), Moreno Fernández (1998), Garrett, Coupland e Williams (2003), Garrett (2010), entre outros. Feito isso, objetiva-se estabelecer os pontos de contato entre os três domínios, justificando o motivo pelo qual se tornam domínios complementares para os estudos sociolinguísticos.

Palavras-chave: Percepções sociolinguísticas. Avaliações subjetivas. Atitudes linguísticas.

\section{CONSIDERAÇÕES PRELIMINARES}

É a fala que faz evoluir a língua: são as impressões recebidas ao ouvir os outros que modificam nossos hábitos linguísticos.

Ferdinand de Saussure

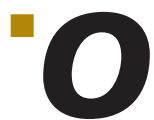

s trabalhos em Sociolinguística no Brasil, especialmente a vertente variacionista, têm se preocupado, em maior parte, com a produção e a descrição do funcionamento da língua em seus diversos contextos reais de uso, o que se torna um empreendimento de grande importância para

O presente trabalho foi realizado com apoio da Coordenação de Aperfeiçoamento de Pessoal de Nível Superior (Capes) - Código de Financiamento 001.

** Universidade Estadual Paulista “Júlio de Mesquita Filho” (Unesp), Araraquara, SP, Brasil. E-mail: unesp.marcus@gmail.com 
o cenário nacional, dado que fornece subsídios para a compreensão da realidade sociolinguística do Português Brasileiro (PB). No entanto, para alcançar uma compreensão mais completa da dinâmica da variação linguística, é preciso não só entender como a linguagem está ligada ao espaço social na maneira como as pessoas falam, mas também incluir a percepção de como ela é ouvida e processada. Deve-se incluir, também, a avaliação subjetiva dos fenômenos variáveis e a atitude linguística manifestada pelos falantes de diferentes comunidades de fala, afinal a lingua em uso envolve, fundamentalmente, o falar, o ouvir, o codificar e o recodificar, o expressar e o interpretar.

Em relação a se expressar, é importante lembrar que, na pesquisa sociolinguística, não se capta apenas as correlações entre os fatores linguísticos e sociais, mas também o posicionamento dos falantes dentro do mundo social e, ainda, como eles constroem e reconstroem o mundo (CAMPBELL-KIBLER, 2009; ECKERT, 2012). Esse posicionamento é um processo complexo que tem, em suas faces, a percepção, a avaliação e as atitudes linguísticas.

Os trabalhos de percepções dos ouvintes partem da premissa de que "o grau de diferença atribuído a pares de variantes difere a depender de seu repertório sociolinguístico" (SORIANO, 2016, p. 2). Em outras palavras, as avaliações realizadas pelos indivíduos sobre as variáveis linguísticas, como é o caso do estudo do (-r) em São Paulo nos trabalhos de Oushiro (2015) e Soriano (2016), "relacionam-se com os padrões sociolinguísticos que adquirem em uma contínua e dinâmica construção de um sistema sociossemiótico de referências" (SORIANO, 2016, p. 2). Esse repertório se arquiteta por suas experiências, perpassando os grupos sociais com os quais se filiam, seu modo de falar e as variantes com que têm mais contato.

O que torna a variável sensivel ou não à avaliação em uma comunidade pode ser atrelado, de certo modo, ao grau de saliência, seja esta linguística, social ou ideológica. Frequentemente, é a correlação desses três fatores que são percebidos na avaliação dos indivíduos e, assim, acabam construindo um padrão de consciência social na comunidade. O nível de consciência social é um aspecto relevante na mudança linguística (WEINREICH; LABOV; HERZOG, 1968) e os estudos de percepção, avaliação e atitudes, ao lado dos estudos de produção e descrição, conforme colocou Drager (2010), são complementares e são capazes de fornecer respaldos importantes para entender não só como a mudança linguística acontece, como também os significados sociais relacionados a determinadas variantes de uma variável.

Nesse sentido, este artigo propõe-se a revisar estudos de percepções sociolinguísticas, avaliações subjetivas e atitudes linguísticas e sua relevância para compreensão da dinâmica da variação e da mudança linguística, bem como articular as vertentes como domínios complementares.

\section{Estudos DE PERCEPÇÃo}

Ao contemplar o papel das percepções dos ouvintes na composição da então dinâmica da variação linguística, é fulcral esclarecer que mesmo os falantes que diferem em suas preferências linguísticas e senso social de significado enquanto falam vão divergir quando escutam/percebem determinada variedade. Afinal, "ouvir os sons" é calcado nas experiências cognitivas, sociais e interativas do 
indivíduo (PRESTON, 2010, 2011; LEVON; FOX, 2014; ROSENBLUM, 2008; BYBEE, 2001) e, desse modo, a variação está condicionada a interferências do ambiente, como a situação de fala, as expectativas do ouvinte a respeito do que vai ouvir e até mesmo o interlocutor (BELL, 1984).

Tão relevante quanto os trabalhos de produção sociolinguística, a percepção é um componente que faz parte do processo geral de uso da linguagem e do desenvolvimento, o que justifica a variabilidade do termo nas pesquisas linguísticas. Mesmo com empregos variáveis, a percepção da fala tem um pouco em comum, já que acontece "de acordo com a bagagem do que já foi experenciado, aprendido e reconhecido. Assim, é claramente dependente de representações [Kohonen, 1989]" (JEKOSCH, 2005, p. 55, tradução nossa) ${ }^{1}$.

As pesquisas teóricas que trazem contribuições sobre o tema da percepção da fala vêm assumindo uma visão mais multidisciplinar, visto que incluem não só áreas que compartilham conhecimentos linguísticos, como a psicolinguística e a sociolinguística, mas também outras áreas do conhecimento, como psicofisica, a neurofisiologia e a inteligência artificial.

Alguns desses trabalhos foram realizados com uma série de dados e uma gama de metodologias diferentes. Uma das pesquisas precursoras, na perspectiva sociolinguística, foi realizada por Labov (1966). Em sua pesquisa sobre o inglês falado na cidade de Nova York, ele especulou que a variação linguística estrutura-se pelo estilo e classe social dos falantes, e que a escolha de formalidade - compreendida por ele como estilo - está conectada à condição social do indivíduo. Para isso, realizou um experimento em que cinco mulheres nova-iorquinas tiveram suas vozes gravadas ao lerem um pequeno texto.

Como etapa subsequente, selecionou-se trechos da leitura que continham diferentes variáveis linguísticas e estas gravações foram expostas a 112 ouvintes também de Nova York que desempenharam o papel de juízes. Pediu-se que os "ouvintes-juizes" simulassem que fossem gerentes de uma grande empresa que estaria fazendo entrevistas de emprego. Após a audição de cada estímulo, os juízes deveriam preencher um questionário em que teriam de enquadrar cada falante em uma das possibilidades vocacionais disponibilizadas (ou, ainda, em uma categoria intermediária entre duas delas): personalidade televisiva, secretária executiva, recepcionista, telefonista, vendedora, operária de fábrica ou nenhuma das opções anteriores.

Os resultados mostraram que as variantes favorecidas pelas classes sociais mais privilegiadas, como é o caso da realização do (-r), receberam julgamentos mais altos na escala de adequação ocupacional do que as variantes que eram, segundo os falantes, de status socioeconômico mais baixo. Essa correlação se reproduziu em todas as classes sociais e grupos étnicos observados. Conclui-se, portanto, que a estratificação social da língua inglesa falada na cidade de Nova York era bastante arraigada, sendo bem reconhecida pelos membros da comunidade linguística.

Os padrões fonológicos podem ser usados, conforme Wolfram e Schilling (1998), para caracterização de aspectos regionais e sociais. O usuário da língua que possui uma boa percepção auditiva, por exemplo, pode se tornar capaz de identificar, de maneira ampla, a vinculação social ou regional de um indivíduo,

1 Trecho original: "Perception occurs therefore against the background of what has already been experienced, learnt and recognized. Thus, perception is clearly dependent on representations [Kohonen 1989]". 
tudo através da percepção dos aspectos fonológicos. A percepção de um fenômeno é uma capacidade humana interessante, visto que o mesmo ouvinte é capaz de distinguir uma vasta quantidade de sons e, mesmo que não seja "treinado para isso", pode atribuir diversas características aos falantes, como sua origem geográfica e social (BAUMANN; BELIN, 2010).

A Dialetologia Perceptual, dentro dos estudos sociolinguísticos, baseia-se em tarefas de desenho de mapa (map-drawing-tasks) para atestar a conexão entre a percepção da fala e a categorização de dialetos. Esse tipo de método objetiva fazer que o ouvinte identifique a origem do falante no mapa de uma região (ou país). Preston (1986), em seu estudo com adultos de diferentes regiões dos Estados Unidos (Indiana, Havaí, Nova York e Michigan), solicitou que os participantes indicassem em um mapa do país as regiões em que, na "opinião" deles, há "formas de falar diferente".

O resultado da pesquisa constatou que os limites dialetais indicados pelos participantes não representaram aqueles obtidos por pesquisas anteriores de produção. A maioria dos participantes ressaltou que Nova York é uma região de "sotaque" único e próprio, enquanto boa parte do país utiliza-se de um falar típico do "sul". Ademais, os integrantes da pesquisa consideraram, conforme marcação feita no mapa, os lugares mais próximos de onde viviam com maior variedade dialetal, enquanto os lugares mais distantes foram marcados como tendo um falar mais homogêneo. O resultado da pesquisa evidencia a afirmação de Jekosch (2005, p. 55), já que a percepção da fala acontece "de acordo com a bagagem do que já foi experenciado, aprendido e reconhecido [...]”.

Na mesma esteira, Gibson (1991, p. 417), sobre percepção, esclarece que esta pode ser apreendida como uma extração de informações sobre as coisas do mundo. Para tanto, perceber algo implica extrair dados e informações importantes sobre os eventos, o que faz com que o ouvinte seja capaz de fazer um julgamento sobre o que é percebido. Fiske e Neuberg (1990) e Rusher e Hammer (2006) apontam que, quando se formam impressões sobre os outros, usa-se um padrão cognitivo que em geral envolve uma categoria social a partir da qual as características individuais, como sexo/gênero e faixa etária, são apreendidas rapidamente durante um curto trecho de fala.

Desse modo, é evidente que se façam inferências sobre falantes a partir do que ouvimos, dado que sem qualquer esforço consciente, quando escutamos uma voz, podemos estabelecer hipóteses consistentes de que seja uma mulher ou um homem, se a pessoa é jovem ou velha, "mano" ou "playboy" ou se é proveniente de determinada região (OUSHIRO, 2015, p. 265). A percepção acaba sendo, como colocou Edwards (1999), um filtro por meio do qual os dados sensoriais são, em um primeiro momento, analisados, e então registrados.

Com vistas a registrar as percepções e avaliações subjetivas dos ouvintes, cresce o número de pesquisas que já incorporaram a técnica de estímulos pareados (matched-guise), desenvolvida por Lambert et al. (1960). Originalmente desenvolvido para estudos em Psicologia Social, o presente método tem oferecido refinado metodológico às pesquisas que buscam alinhar produção e percepção no terreno da sociolinguística. Giles e Billings (2004 apud OUSHIRO, 2015, p. 268) a avaliam "como uma ferramenta poderosa e elegante que, ao controlar uma série de variáveis com a criação de estímulos comparáveis, permite averiguar apropriadamente o papel da linguagem na formação de impressões e julgamentos sociais". 
Grosso modo, a técnica consiste na gravação prévia de falantes e manipulação de estímulos para obtenção de pares pareados. Com ela, avaliações encobertas podem ser extraídas, já que se perguntado abertamente a um falante a avaliação dele sobre determinada variável, ele pode fornecer informações que não correspondam, verdadeiramente, à sua opinião. No caso do estudo de Lambert et al. (1960) foram quatro falantes bilingues de Montreal (Canadá) que leram o mesmo texto em inglês e francês. A essas, adicionaram-se duas gravações distratoras. Assim, apresentaram-se as gravações aos “juízes” que, após ouvirem os guises, emitiram reações subjetivas a partir do que tinham percebido e, ainda, atribuíram a eles 14 características pessoais, organizadas em escalas de diferenciais semânticos de seis pontos.

Campbell-Kibler (2006, 2009), através da técnica de estímulos pareados, realizou um estudo que investigou os significados sociais das variantes de (ING), como em working e workin' no inglês norte-americano, e o papel de fatores contextuais na formação de impressões e julgamentos dos ouvintes. Segundo Oushiro (2015, p. 271):

[...] seu estudo incorporou uma série de inovações metodológicas, dado que se utilizou de conversas naturais em vez de leituras para a criação de estímulos; a manipulação digital de gravações para obter estímulos pareados; a condução de entrevistas "abertas" antes da aplicação de questionários, a fim de determinar que tipos de reações surgem naturalmente ao se escutarem as gravações e, por fim, a coleta de questionário via redes sociais na internet.

Oito falantes contribuíram para a gravação dos estímulos pareados, todos estratificados por sexo/gênero e região de origem. Desse modo, cada participante da pesquisa ouviu apenas um dos estímulos - [In] velar/[In] alveolar - e então respondeu sobre as impressões que tiveram a respeito do falante. Em seus resultados mais gerais, Campbell-Kibler (2006) mostrou que os ouvintes julgaram os falantes como mais educados, articulados e inteligentes diante do estímulo com a variante velar, enquanto diante da variante alveolar os falantes foram percebidos como casuais, descuidados e preguiçosos. A pesquisadora concluiu, como resumiu Oushiro (2015, p. 271), que os significados sociais múltiplos - nivel de escolaridade, eloquência, formalidade, região etc. - dependem de fatores contextuais, como o conteúdo da mensagem e qualidades pessoais atribuídas aos falantes pelos ouvintes.

Alguns estudos brasileiros de percepções sociolinguísticas foram realizados (baseando-se nesta mesma técnica e em outras) e, com isso, ganharam destaques importantes. No presente trabalho, por limitação de páginas, trata-se apenas de dois desses trabalhos, o que não exclui a importância das demais obras que avaliam a percepção de ouvintes em relação a um fenômeno variável ou mais especificamente a uma variante de uma variável linguística.

O trabalho de Oushiro (2015), por exemplo, com uma empreitada de analisar as relações entre processos de variação e mudança linguística e os significados sociais e identidade linguística por meio de usos linguísticos selecionou quatro variáveis do português paulistano: a realização do (e) nasal como monotongo ou ditongo; a pronúncia de (-r) como tepe ou retroflexo; a alternância de número na concordância verbal; e a alternância entre a marca zero e a marca explícita de concordância nominal. Para isso, a pesquisadora realizou entrevistas sociolinguísticas com falantes de São Paulo para mapear e analisar, a partir 
da produção, as variáveis selecionadas. Após essa etapa, desenhou-se um experimento de percepção sociolinguística e, considerando os resultados obtidos nos resultados de produção e por ser uma variante muito saliente no português brasileiro, optou-se por explorar, de forma pormenorizada, apenas as variantes tepe e retroflexa.

Especificamente sobre percepções sociolinguísticas, Oushiro (2015) buscou examinar o efeito das variantes tepe e retroflexa nas percepções de ouvintes moradores de São Paulo e, a partir delas, propôs um modelo de como certos significados sociais se associam a determinados usos linguísticos. Nas palavras da pesquisadora, "a variável foi escolhida por ser uma das mais salientes no português brasileiro e por ter apresentado forte estratificação social no português paulistano" (OUSHIRO, 2015, p. 265). Os métodos empregados por ela basearam-se no estudo de Campbell-Kibler (2006) e contou, especificamente, com a preparação dos estímulos produzidos por quatro falantes paulistanos (sendo dois homens e duas mulheres de nivel superior de escolaridade), realização de entrevistas "abertas" de percepção e, por último, formulação e aplicação de questionários cujas respostas possam ser quantificadas.

A pesquisadora concluiu que os resultados apontaram para avaliações concordantes entre si sobre os significados sociais de (-r) na cidade de São Paulo. O principal significado das variantes está associado a geografia, capital versus interior e centro $v$ s. periferia, e tais significados "se estendem para o status relativo dos falantes na comunidade e, em menor grau, a inferências sobre o caráter dos indivíduos" (OUSHIRO, 2015, p. 320). Em síntese, como mostraram as correlações mais significativas, o retroflexo é julgado mais negativamente em traços que se referem ao status dos falantes (classe social, nível de escolaridade, formalidade, centralidade do bairro, articulação e sofisticação) e mais positivamente em características associadas a solidariedade e dinamismo (simplicidade, sinceridade, trabalho e solidariedade).

A referida pesquisa torna-se uma grande referência para os estudos sociolinguísticos não só pelo refinamento metodológico dos dados ou por utilizar a técnica de matched guise para avaliação de percepção, mas também por congregar perfeitamente estudos de produção, covariação e percepção sociolinguística - ainda mais se considerarmos que a comunidade de fala por ela escolhida (São Paulo) apresenta poucos estudos de variação linguística na literatura especializada.

Sobre a percepção do (-r) em São Paulo, Soriano (2016) realizou um importante estudo que visou verificar como as características sociais dos ouvintes, bem como o significado social das variantes linguísticas, influenciam no grau de diferença acústica atribuída a cinco variantes de (-r) em coda na cidade de São Paulo: 1 . vibrantes com três batidas; 2. tepe (vibrante simples); 3. vibrante com duas batidas; 4. aproximante aveolar; e 5. aproximante retroflexa. Para isso, foi utilizada apenas uma "voz" para o experimento: um homem de 40 anos, linguista e residente em São Paulo há mais de 20 anos. Após definido o experimento, 109 moradores da capital foram convidados a atribuir diferenças a pares formados pelo mesmo item lexical, por exemplo, "a palavra virtude primeiro pronunciada com o tepe e depois com o aproximante alveolar".

Soriano (2016) buscou elaborar dez pares de estímulos para cada item lexical selecionado como objeto de análise, certificando de que todas as combinações possiveis entre as cinco variantes do (-r) fossem realizadas. Após aplicação on-line do teste, concluiu que, quando os pares de estímulos foram analisados 
separadamente, observou maior saliência em relação ao retroflexo e à vibrante com três batidas. Em outras palavras, o modo como os participantes da pesquisa (ouvintes) percebem e atribuem as diferenças varia a depender de seu repertório sociolinguístico. Mais especificamente, nas análises multivariadas, a pesquisadora observou que as variáveis $\mathrm{Par}^{2}$, a região de nascimento, o local de residência, a variante que ele reconhece em sua própria fala e o sexo/gênero correlacionam-se positivamente. Tal como a pesquisa de Oushiro (2015), esta investigação contribui de forma profícua para a literatura sobre percepções sociolinguísticas, dado que a autora desenha um experimento refinado utilizando diferentes métodos, tal como Campbell-Kibler (2006) e Oushiro (2015), e, com eles, manipula as variáveis em múltiplos disfarces (guises).

Tendo em vista os estudos anteriormente resumidos, uma importante ressalva deve ser feita, dado que embora o trabalho do Lambert et al. (1960) aqui se apresenta, dentro da seção de percepção, este estudo é considerado o percursor nos estudos de atitudes linguísticas no campo da Psicologia Social. No entanto, como a técnica de matched guise desenvolvida por ele e seus colegas é a principal ferramenta utilizada nos experimentos sociolinguísticos de percepção, justifica-se o porquê de mencioná-la aqui, mesmo que brevemente.

Além disso, ao observar que os estudos de percepção têm como objetivo primordial compreender as reações encobertas dos falantes em relação a uma língua ou variedade, a pesquisa do Lambert et al. (1960) pode, nesse sentido, estar aqui arrolada, afinal o estudo avaliou a associação de certos significados sociais ao emprego de línguas diferentes, como ocorre em algumas pesquisas de percepção sociolinguística.

Este é um bom exemplo de como existe uma confluência entre percepção e atitude linguística. Um trabalho marco da Psicologia Social que inaugura pesquisas dentro das atitudes linguísticas é, também, o responsável por fornecer um método robusto para investigação de reações encobertas (percepção). A tradição sociolinguística mostra como essa ciência tem se destacado por se valer de diferentes metodologias para alcançar resultados ainda mais refinados nas pesquisas de produção e percepção. No campo das pesquisas variacionistas e graças aos estudos da terceira onda ${ }^{3}$, os experimentos realizados à luz da percepção estão se especificando e deslocando o interesse sobre diferentes linguas ou variedades linguísticas para, como sinalizou Thomas (2002), o papel de variantes específicas na formação de impressões sociais.

Alguns trabalhos que se enquadram na terceira onda da Sociolinguística (ECKERT, 2000) visam determinar as percepções dos ouvintes acerca de variáveis linguísticas e em quais "pistas" fonéticas eles se baseiam para fazer inferência a respeito do dialeto ou de características pessoais do falante (CAMPBELL-KIBLER, 2006; PODESVA, 2007; LEVON, 2007; MENDES, 2014; OUSHIRO, 2015; SORIANO, 2016, entre outros).

Após o estudo de Campbell-Kibler (2006), tais estudos têm contato com novos métodos para os desenhos experimentais de percepções, sendo eles: 1. a preparação de estímulos pareados a partir de trechos de fala natural, em geral feito no programa Praat (BOERSMA; WEENINK, 2014); 2. realização de entrevis-

\footnotetext{
2 É o contraste entre as próprias variantes e inclui as diferenças de modos de articulação (vibrantes e aproximantes), número de batidas a língua nos alvéolos (3, 2 e 1) e graus de retroflexão (aproximante e retroflexo).

3 Para mais informações sobre a terceira onda da Sociolinguística, ver Eckert (2000).
} 
tas “abertas" de percepções, que não apresentam um roteiro predefinido e 3. formulação e aplicação de questionários estabelecidos em plataformas on-line como Google Forms ou SurveyMonkey - em geral, pensando na sistematização do questionário, eles são organizados em escalas de diferenciais semânticos de cinco a seis pontos.

\section{Avaliação sociolinguística}

A avaliação é uma prática frequente nos diversos contextos da sociedade e incide sobre os múltiplos comportamentos sociais. Sendo a lingua um comportamento social, não poderia ser diferente, considerando que está sujeita à avaliação de quem fala, de um lado, e de quem escuta, do outro. Tais avaliações subjetivas podem ou não se materializar em complexos processos de reações subjetivas que evidenciem como uma variedade linguística é avaliada, positiva ou negativamente.

Em relação a esse assunto, Weinreich, Labov e Herzog (doravante WLH) (1968), ao discutirem os fundamentos empíricos para uma teoria da mudança linguística, elencaram cinco princípios que possibilitam discutir e descrever como os processos de variação e/ou mudança acontecem, se difundem, se encaixam e são avaliados socialmente nas comunidades de fala. Esses princípios foram intitulados pelos autores como "problemas" que buscam consolidar o que os estudos dialetais da época estavam propondo. Os problemas são: 1. o problema dos fatores condicionantes; 2. o problema da transição; 3. o problema do encaixamento; 4. o problema da avaliação e 5. o problema da implementação.

Para a revisão em questão, interessa-nos observar o que os autores postularam em relação ao problema da avaliação. Segundo WLH (1968), esse problema diz respeito à observação de quais são os correlatos subjetivos - avaliação subjetiva - apresentados pelos falantes/ouvintes acerca da variedade linguística compartilhada pelos membros da comunidade de fala, visto que esta pode contribuir decisivamente para a propagação ou interrupção de um fenômeno sociolinguístico. Assim sendo, qualquer variedade linguística, dialeto ou língua é objeto de avaliação sociolinguística.

A apreciação sociolinguística de dialetos, variedades e/ou variantes está vinculada à capacidade cognitiva do falante e, ao mesmo tempo, a valores socialmente impostos. Labov (2010, p. 2, tradução nossa) definiu os fatores cognitivos como:

[...] fatores que influenciam a aquisição do sistema linguístico que transmite informações sobre o estado de coisas - sobre o que está sendo dito, em vez da forma ou estilo de expressão. O estudo dos efeitos cognitivos da mudança de som para medida das habilidades do ouvinte com o intuito de identificar os fonemas no fluxo da fala e, assim, recuperar as palavras pretendidas pelo falante ${ }^{4}$.

Essa recuperação de fatores cognitivos, alinhados a aspectos culturais e sociais, possibilitam a revelação acerca de informações e características sociais dos informantes, das relações de destinatários ou de apresentação e usos de

4 Trecho original: "As factors that influence the acquisition of the linguistic system that conveys information on status of affairs - on what is being said rather than on the manner or style of expression. The study of the cognitive effects of sound change calls for measure of listener's abilities to identify the phonemes in the stream of speech and so to retrieve the words intended by the speaker". 
itens linguísticos nas comunidades de fala. Posto isso, deve-se observar que a avaliação sociolinguística toma, como constituintes, duas dimensões formadoras: "dimensão objetiva e dimensão subjetiva" (FREIRE, 2016, p. 48), sendo a primeira responsável por tomar o fato linguístico como fonte reveladora do ato de avaliar (por exemplo, uma variante linguística) e a segunda a que toma como referência o falante (ou seja, as características sociodemográficas).

Clopper e Pisoni (2005, p. 333, tradução nossa) destacam que "diversos estudos revelam que ouvintes ingênuos estão cientes da variação linguística na medida em que eles podem imitá-la e usá-la para identificar de onde as pessoas são e para fazer julgamentos sobre as características social dos locutores" ${ }^{\text {. Nes- }}$ te aspecto, nota-se que a percepção do ouvinte pode ser tão precisa que, segundo Labov (2010), chega a se apoiar em qualidades fonéticas para realizar a identificação da origem de um informante ou para reconhecer e distinguir os traços linguísticos que fornecem pistas para sinalizar a classificação dialetal. Em outras palavras, os falantes nativos, segundo Clopper e Pisoni (2005), podem identificar categorias sociais e linguísticas, explicitamente, em dados de fala, separando aqueles que não são familiares à sua variedade.

Um célebre trabalho brasileiro que investiga a avaliação social da língua é o de Cardoso (2015) - a tese foi originalmente defendida em 1989, mas só recentemente foi digitalizada. O trabalho objetivou atestar a avaliação dos falantes aracajuanos em relação ao seu próprio dialeto e estabelecer uma relação entre as avaliações (positivas e negativas) e outras variedades regionais estudadas - a carioca, a baiana e a alagoana. Para isso, foram utilizados protocolos como um questionário de avaliação subjetiva e a gravação de estímulos pareados (matched-guise). A aplicação dos protocolos foi dividida em dois momentos: o primeiro sem o estímulo gravado, e o segundo com a técnica do matched-guise. Participaram da pesquisa 144 ouvintes, 72 de cada sexo, entre 14 e 70 anos de idade.

Cardoso (2015) concluiu, em relação à primeira aplicação sem o estímulo de voz, que os aracajuanos, independentemente de idade e escolaridade, avaliaram de forma positiva a variedade nativa. Observou também que não havia entre os participantes um reconhecimento nítido de diferenças de nível linguístico. Além disso, a variável escolaridade mostrou ser responsável por determinar a avaliação dos informantes em relação aos "desvios de norma". Quanto mais escolarizado os informantes, maior a rejeição a erros de "concordância verbal", troca de "l" por "r" ou queda do " $r$ " final.

A linguista apontou que "as respostas dadas aos questionários sem a fita-estímulo não se mantêm no questionário com a fita-estímulo" (CARDOSO, 2015, p. 118). Com a apresentação dos estímulos, a variável sexo não mostrou diferenças estatisticamente significativas. Em outras palavras, tanto o sexo masculino como o feminino quando ouviram o estímulo VI - falante com nível de escolaridade superior (com diploma) - avaliaram positivamente, sendo a mais aceita, a menos aceita foi dividida entre o falante com o $2^{\circ}$ grau incompleto e o falante com o $2^{\circ}$ grau completo. Em suma, Cardoso (2015) notou que as variáveis escolaridade e idade apresentam resultados semelhantes a sexo, ou seja, todos avaliaram o estímulo VI como a mais aceita, as demais avaliações variavam entre os estímulos VIII e IX.

5 Trecho original: "[...] diverse studies reveal that naïve listeners are aware of linguistic variation on the extent that they can imitate it, use it to identify where people are from and to make judgments about social characteristic of the talkers". 
Garcia (2018) averiguou a avaliação subjetiva de moradores que se autodenominam bonfinenses e os moradores dos condominios adjacentes a Bonfim Paulista em relação ao uso da concordância verbal de terceira pessoa do plural. Para isso, a pesquisadora realizou entrevistas sociolinguísticas para mapear os resultados na comunidade ainda não explorada e elaborou um teste de atitudes linguísticas que circulou on-line. Por mais que os resultados sobre o uso da CV se alinhassem a pesquisas linguísticas já realizadas, a ordem de seleção das variáveis, tanto linguísticas como extralinguísticas, não coincidiram entre as duas comunidades - o que demonstrou que a relevância dessas variáveis é, de alguma forma, distinta para cada grupo.

Os resultados das avaliações dos informantes evidenciaram, tal como explicitado em Garcia (2018), que a variedade linguística avaliada de forma positiva foi associada ao falante morador de condomínio, ou seja, eles foram associados sempre ao uso maior de plural no verbo concordante ao sintagma nominal plural. Enquanto a variedade mais estigmatiza, a ausência da concordância, foi atrelada aos bonfinense - "indivíduos que carregam valores sociais atrelados à vida rural" (GARCIA, 2018, p. 133). Em outros termos, os moradores de condomínio estão mais associados às normas linguísticas de prestígio, ao estilo de vida mais urbano e, sobretudo, mais escolarizado, à medida que os bonfinenses estão, como mostrou o teste, relacionados ao estilo de vida mais pacato e ao grau de escolarização menor.

Os estudos sociolinguísticos que objetivam examinar a avaliação sociolinguística têm se apropriado de um conjunto de instrumentos e técnicas de diferenças semânticas para verificar aspectos sociais, pessoais e linguísticos, entre outros, que podem ser vinculados aos usos da lingua (FOULKES; KHATTAB; YEGGER-DROR, 2010). Além disso, pesquisas como as de Cardoso (2015) e Garcia (2018) já constataram que a avaliação de uma variedade ou variante pode receber julgamento mais saliente em determinadas comunidades de fala do que em outras, o que acaba refletindo que dimensões diferentes agem em comunidades diferentes, visto que os padrões sociolinguísticos preexistem dentro de toda a comunidade que compartilha diferentes aspectos sociolinguísticos e não a um indivíduo em específico.

\section{Atitudes linguísticas}

O conceito de atitude foi discutido, inicialmente, pelos pesquisadores da Psicologia Social que buscavam respostas para compreender certos comportamentos humanos e suas motivações. A escola norte-americana de psicologia social, de modo geral, colocava a linguagem como um aspecto periférico no estudo de atitudes, diferentemente da escola europeia, que balizou investigações empíricas que envolvessem a linguagem.

Lambert assumiu, na década de 1960, a linguagem como um elemento determinante para suas investigações, uma vez que os pesquisadores europeus a dispensavam. Por essa razão, o pesquisador é considerado o precursor nos estudos de atitudes linguísticas e, conforme colocado anteriormente, reconhecido também por desenvolver a técnica de matched-guise; cuja a definição é:

[...] as reações de ouvintes (referidos como juízes) a gravações de um número de falantes perfeitamente bilingües lendo uma passagem de dois minutos uma vez em uma de suas línguas (ex.: francês) e, depois, uma tradução equivalente da 
mesma passagem em sua segunda lingua (ex.: inglês). Grupos de juízes são levados a ouvir essas séries de gravações e a avaliar as características da personalidade de cada falante tanto quanto possível, usando pistas de fala apenas (LAMBERT, 1967, p. 93).

A presente técnica permite manipular características que são ora linguísticas ora sociais sobre determinada língua ou dialeto objetivando observar as reações de falantes a respeito dessas características ou variações. Lambert et al. (1960), para o estudo do bilinguismo franco-inglês em Montreal, utilizaram informantes bilingues e gravaram dois textos de cada um - sendo um em francês (o trecho original) e o outro traduzido, proficientemente, para o inglês. Quatro falantes foram gravados lendo as duas passagens e, a essas oitos leituras, duas gravações como distratoras foram adicionadas e apresentadas a 130 ouvintes-juízes estudantes universitários de duas faculdades de Montreal, distribuídos equilibradamente em anglófonos e francófonos.

Para cada um dos estímulos, os participantes da pesquisa deveriam reagir, numa escala de "muito pouco" a "muito", as características pessoais organizadas em seis pontos. O objetivo geral dos autores era atestar se os mesmos quatro falantes receberiam avaliações diferentes a depender do estímulo - se inglês ou francês. Em resumo, os ouvintes-juízes, tanto os anglófonos como os francófonos, avaliaram os estímulos em inglês mais favoráveis, sobretudo em relação a características da escala que relacionava a questão socioeconômica, como é o caso de liderança, ambição e aparência.

No artigo de Williams intitulado Some research notes on dialect attitudes and stereotypes (1973), partindo da hipótese de que os falantes tendem a empregar um conjunto estereotipado de atitudes como ponto de apoio para a avaliação quando apresentados a uma amostra de fala, o presente trabalho empreendeu avaliar aspectos de atitudes que entram em jogo quando as pessoas fazem julgamentos de fala. Para isso, foram selecionados professores que refletiram sobre amostras de fala de crianças brancas, negras e mexicanas, de status social médio e baixo.

Como medida técnica para avaliação das atitudes, utilizaram-se escalas de diferenciais semânticos que envolveram a avaliação de um conceito ou estímulo por meio de pares adjetivos. Mesmo na ausência de estimulos gravados, o pesquisador constatou que alguns professores mostraram-se propensos a antecipar atitudes em direção a uma criança em particular. Essas e outras atitudes verificadas na pesquisa, conforme mostrou Williams (1973), refletem que os estereótipos se sobressaem na avaliação dos docentes, mesmo diante de amostras de fala.

Com isso, observa-se que "as atitudes dos indivíduos estão presentes, mas dormentes na maioria das vezes; elas se expressam na fala ou outro comportamento somente quando um objeto de atitude é percebido" (OPPENHEIM, 1966 , p. 106) ${ }^{6}$. Ainda nas palavras do pesquisador, "as atitudes são reforçadas pelas crenças - o componente cognitivo - e muitas vezes atraem sentimentos fortes - o componente emocional - que levará a formas específicas de comportamento - o componente de tendência de ação" (OPPENHEIM, 1966, p. 106).

6 Trecho original: "The individual's attitudes are present but dormant most of the time; they become expressed in speech or other behavior only when the object of the attitude is perceived". 
Isso implica dizer que uma pessoa pode manifestar atitudes positivas ou negativas acerca de um estímulo e, ainda, algumas delas podem apresentar graus de intensidade variáveis ou ser mais resistentes que outras, dado que algumas envolvem uma filosofia de vida enquanto outras são superficiais e estão sujeitas a repetidas mudanças.

Lambert e Lambert (1972, p. 78, grifo nosso) apresentam a definição clássica de atitudes linguística quando asseguram que:

Atitude é uma maneira organizada e coerente de pensar, sentir e reagir em relação a pessoas, grupos, questões sociais ou, mais genericamente, a qualquer acontecimento ocorrido em nosso meio circundante. Seus componentes essenciais são os pensamentos e as crenças, os sentimentos (ou emoções) e as tendências para reagir.

Na esteira da definição, Sarnoff (1970 apud GARRETT; COUPLAND; WILLIAMS, 2003, p. 2-3) estabelece que atitude "é uma disposição para reagir favoravelmente ou desfavoravelmente a uma classe de objetos" ${ }^{7}$. Nesse sentido, a definição de Sarnoff (1970) acaba aliando atitude à noção de avaliação. Garrett (2010, p. 1) afirma que "atitudes linguísticas permeiam nossas vidas diárias. Elas nem sempre são articuladas publicamente e, na verdade, nem sempre estamos conscientes delas".

Assim sendo, a materialização das atitudes linguísticas, sejam elas positivas ou negativas, é uma realidade que o usuário da língua manifesta baseando-se em uma série de percepções, avaliações, estereótipos etc. que circulam na comunidade de fala na qual ele está inserido. A partir disso, as atitudes (articuladas às crenças linguísticas) podem constituir um meio de representação que os falantes possuem de si ou dos outros em relação ao ato de falar, confirmando o que aponta Moreno Fernández (1998) ao esclarecer que a língua se torna, em seu uso, um simbolo de relacionamento de um grupo ou entre grupos socialmente estabelecidos.

As discussões conceituais referentes às atitudes linguísticas tornaram-se bastante produtivas para as análises sociolinguísticas e, portanto, acabam remetendo-se a diferentes significações. Entretanto, de maneira geral, as atitudes linguísticas têm sido apontadas como a "predisposição a um comportamento" que pressupõe, sobretudo, que tenha havido um processo cognitivo anterior de percepção e avaliação subjetiva.

Nesse sentido, uma "predisposição positiva" pode fazer com que uma mudança linguística se efetive mais rapidamente e, ainda,

[...] que em certos contextos se predomine o uso de uma língua em detrimento de outra, que o ensino-aprendizagem de uma lingua estrangeira seja mais eficaz $e$ que certas variedades linguísticas se tornem mais salientes em estilos mais formais (MORENO FERNÁNDEZ, 1998, p. 179) ${ }^{8}$.

Outra questão fundamental é verificar a intrínseca relação entre as atitudes linguísticas e os fatores não-linguísticos. Labov (2008 [1972], p. 251) defende que: "se um certo grupo de falantes usam uma variante particular, então os

\footnotetext{
Trecho original: [...] "is a disposition to reach favourably or unfavourably to a class of objects".

8 Trecho original: [...] "que en ciertos contextos predomine el uso de una lengua en detrimento de otra, que la enseñanza-aprendizaje de una lengua extranjera sea más eficaz, que varía las variantes lingüísticas se confinen a los estilos cuidados".
} 
valores sociais atribuídos ao grupo serão transferidos para a variante". A esse respeito, Bisinoto (2007, p. 24) completa:

As avaliações manifestas e encobertas, subjetivas e objetivas, mais ou menos conscientes, relativas à linguagem dos homens numa sociedade plural, têm a propriedade de fundar e governar tanto as relações de poder quanto o prestígio ou o desprestígio das formas linguísticas, estabelecendo seletividades, evidenciando preconceitos.

Assim, fica claro que as atitudes não são características inatas às pessoas, mas sim formadas e aprendidas no processo de socialização. Lambert e Lambert (1972) afirmam que as atitudes são hábitos complexos, no sentido de que são formas aprendidas de ajustamento. Desse modo, nota-se que a atitude é um processo dotado de certas etapas, e não simplesmente um resultado. A percepção de determinado objeto e a demonstração ativa de um indivíduo são precedidas e corroboradas no processo de socialização, já que o objeto deve ser elevado a uma dimensão avaliativa no sistema de crença e valores do falante para, consequentemente, ascender uma eventual reação emotiva sobre o objeto.

Para medir atitudes, os estudiosos da área já apresentaram um consenso sobre a visão tripartida das atitudes linguísticas. Para os pesquisadores, a estrutura interna das atitudes é constituída por três componentes: cognitivo, afetivo e comportamental (ROSENBERG; HOVLAND, 1960; KOTHANDAPANI, 1971; AYZEN; FISHBEIN, 1980; BRECKLER, 1984; GARRETT; COUPLAND; WILLIAMS, 2003; CAMPBELL-KIBLER, 2006; GARRETT, 2010; KAUFMANN, 2011).

De forma detalhada, pode-se verificar esses componentes da seguinte maneira: por exemplo, em relação ao componente cognitivo, o falante pode apresentar crenças, conhecimentos e pensamentos acerca de uma variedade ou variante linguística específica; quanto ao elemento afetivo, pode-se demonstrar emoções e sentimentos por meio de uma avaliação negativa ou positiva; por fim, todo o falante age e reage diante de formas linguísticas, isto é, tem uma conduta ou comportamento para concretizar sua atitude.

Em concordância com essas informações, defende-se que a investigação sociolinguística de atitudes linguísticas deve demonstrar as relações existentes na visão tripartida da estrutura interna de fenômenos sociais e, ao mesmo tempo, explicitar os aspectos mais saliente das abordagens adotadas.

Em Freitag e Santos (2016), por exemplo, considerando a visão tripartida, avaliaram as atitudes inconscientes dos participantes da pesquisa ante à variação oclusiva [t] e [d] vs. africada [tf] e [d3] em Sergipe. Para isso, realizaram um verbal guise 9 aplicado a 18 participantes do sexo masculino e 18 do sexo feminino, todos estudantes da Universidade Estadual Federal de Sergipe e pertencentes a faixa etária entre 18 e 41 anos de idade. Em linhas gerais, os pesquisadores concluíram que os indivíduos universitários aracajuanos reagiram positivamente à forma palatalizada indicando-a como a de mais prestígio, ao contrário da forma não-palatalizada que ainda sofre estigma social.

Assim, os estudos sobre atitudes linguísticas, desde o primeiro estudo com Lambert et al. (1960) até os mais recentes, vêm prosperando e, consequentemente, ramificaram-se em alguns grupos: 1 . aqueles que exploram as atitudes gerais em relação à língua e, especificamente, habilidades linguísticas (SANTOS,

9 É uma variante da técnica matched guise em que estímulos de diferentes falantes são ouvidos, enquanto o matched guise consiste na manipulação de um mesmo informante. 
1996; CYRANKA, 2007; AGUILERA, 2008; REZENDE, 2014); 2. os que investigam percepções sobre a língua e seus falantes e de que modo essas percepções poderiam favorecer ou desfavorecer a mudança linguística (LABOV, 2008; RYLES; GILES; SEBASTIAN, 1982; MORENO FERNÁNDEZ, 1998; THOMASON, 2001; BISINOTO, 2007; AGUILERA, 2008); e 3. e os que se ocupam de questões como escolha e uso de uma língua (BERGAMASCHI, 2006; MOLINA, 1998).

\section{Percepções, AVAliações E ATITUdes: TRÊS domínios Complementares}

Os estudos de percepção e avalição buscaram nos trabalhos de atitudes linguísticas, ou mais especificamente na técnica de matched-guise, caminhos para aperfeiçoarem seus objetivos e metodologias. O contato entre esses três domínios (percepção, avaliação e atitudes) resultou em pontos de intersecção, uma vez que os estudos de avaliação e percepção, dentro da empreitada sociolinguística, podem ser interpretados como desdobramento dos estudos de atitudes linguísticas inaugurados por Lambert et al. (1960). Essa intersecção pode ser ilustrada como uma atividade circular (cf. Figura 1), afinal as pesquisas hodiernas, em sua maioria, têm usado os três domínios como sinônimos, não só pelo uso da técnica de estímulos pareados, já que outras técnicas produtivas têm sido utilizadas, como também pela dificuldade de delinear, com exatidão, fronteiras que separem um dominio do outro.

A circularidade dos três domínios pode ser observada em estudos mais recentes de percepção que permitem a criação de estímulos com falas reais, utilizando-se de softwares como o Praat (BOERSMA; WEENINK, 2014) e o PsychoPy v1.82.01. Esses estímulos são apresentados para “ouvintes-juízes" para que eles possam avaliar, por exemplo, como certos significados sociais se associam a determinados usos linguísticos, por meio de reações inconscientes e, também, de avaliações subjetivas que são possiveis de extrair utilizando técnicas como as escalas de diferenciais semânticos, matched-guise e verbal-guise. Tais percepções e avaliações subjetivas podem se materializar em atitudes (positivas, negativas e neutras) acerca do fenômeno que foi colocado na dimensão avaliativa.

Figura 1 - Círculo permanente de práticas sociolinguísticas

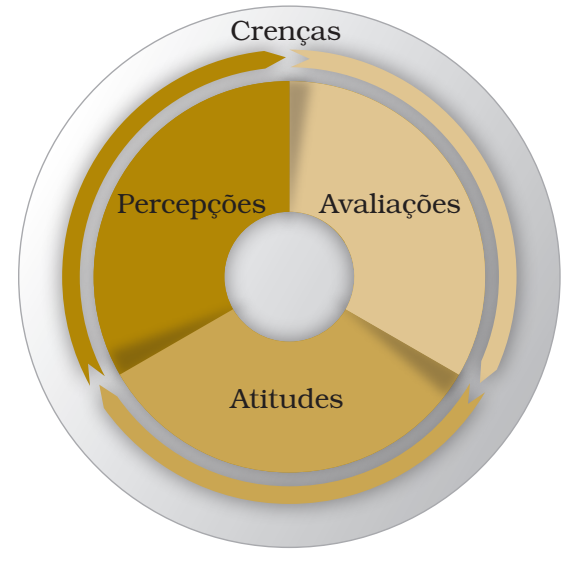

Fonte: Elaborada pelo autor. 
Um exemplo desse círculo permanente de práticas sociolinguísticas é quando um objeto ou dado linguístico é colocado na dimensão avaliativa. Em geral, convidam-se membros de determinadas comunidades para avaliarem um fenômeno linguístico em específico, seja este na modalidade oral ou escrita. Antes da tarefa de avaliação propriamente dita, um dado linguístico precisa ser "percebido" para então ser "avaliado" e, a partir disso, emergir "atitudes" variáveis em relação ao dado linguístico percebido. Nesse sentido, dado que seria impossivel, se não inadequado, perfilar divisões rígidas para tais conceitos, estes têm sido utilizados como sinônimos na tradição sociolinguística. Em outros termos, são domínios interpretados como indissociáveis, tal como a relação entre homem-língua-sociedade, uma espécie de uma tríade que cada componente depende do outro para existir e separá-los é reduzir sua "força". Analogicamente, o conceito de crença, embora não articulado ao longo do texto, é o ponto-chave para que todos os outros domínios coexistam. Afinal de contas, é dentro do componente de crenças e por meio delas que os demais domínios se influenciam mutuamente.

Para Barcelos (2007, p. 38), as crenças são:

[...] uma forma de pensamento, construções da realidade, maneiras de ver $e$ perceber o mundo e seus fenômenos, co-construídas em nossas experiências resultantes de um processo interativo de interpretação e (re)significação. Como tal, crenças são sociais (mas também individuais), dinâmicas, contextuais $e$ paradoxais.

Barcelos (2007, p. 114) esclarece que as crenças são, então, "socialmente construídas e contextualmente situadas". As crenças, à medida que as pessoas interagem e modificam suas experiências, "incorporam as perspectivas sociais, pois nascem no contexto de interação e na relação com os grupos sociais" (BARCELOS, 2007, p. 114). Nesse sentido, a autora ainda relembra o fato de que as crenças podem ser paradoxais e contraditórias, já que, ao mesmo tempo que permeiam os espaços sociais, as crenças também podem ser individuais e únicas, porque cada falante assimila uma experiência de modo particular.

Este componente é o responsável por irrigar toda a prática ilustrada anteriormente, e por tratar-se de um componente que se fixa na mente das pessoas como um hábito, não pode ser caracterizada necessariamente como a materialidade da prática; pelo contrário, qualquer um dos domínios citados recebe influência direta (ou indireta) da crença, sendo que ela é responsável não só por refletir nossos posicionamentos, como também nossos preconceitos e identidade.

Complementar a isso, destaca-se que a relação complexa e inerente entre crença, atitudes, avaliação e percepção é o que permite que os indivíduos se valham de armas para demarcar seu espaço cultural, seu perfil de comunidade e de grupo social. Ainda, na mesma esteira, o momento em que o falante se posiciona/reage/percebe ou avalia positiva ou negativamente determinada variedade, ele se reveste de uma identidade que o diferencia de um grupo, etnia ou povo.

\section{À GUISA DE CONCLUSÃo}

As atitudes, a percepção e a avaliação subjetiva não são uma característica inata às pessoas; elas são formadas e apreendidas no processo de socialização. Como visto, Lambert e Lambert (1972) alegam que as atitudes, por exemplo, são 
hábitos complexos no sentido que são formas aprendidas de ajustamento. Desse modo, nota-se que os domínios são um processo dotado de certas etapas e não simplesmente um resultado. Por essa razão, a crença é um componente importante responsável por irrigar a prática sociolinguística que poderá fornecer, depois de certas etapas, a materialização de uma atitude linguística.

Os domínios, além de complementares, fornecem uma contribuição significativa aos estudos sociolinguísticos, por exemplo, já que ampliam as investigações para além do nivel descritivo de produção, desvelando a maneira pela qual as percepções, avaliações e atitudes linguísticas afetam o processo de constituição da identidade pela lingua e também pelo discurso.

Embora os trabalhos aqui resenhados tenham sido apresentados em seções separadas, isso não equivale a dizer que os autores perfilaram fronteiras sobre os conceitos e por isso a escolha em coloca-los nas respectivas seções; pelo contrário, em especial quando se tratavam de atitudes e avaliações, os conceitos são usados indiscriminadamente como sinônimos, sem a preocupação de delinear coerentemente a diferença entre os dois. Tanto o conceito de atitude postulado por Lambert e colegas, quanto o de avaliação subjetiva delineado por Weinreich, Labov e Herzog podem ser trabalhados de forma equivalente e complementar, uma vez que eles têm o mesmo ponto em comum que é verificar, de forma organizada e coerente, as atitudes/avaliações de falantes. Mesmo que o conceito de Lambert e Lambert (1972) sobre atitudes linguísticas seja mais genérico do que o postulado por WLH (1968), eles não se tornam discrepantes, a provável diferença está no objeto avaliado, enquanto os sociolinguistas avaliam, quase que exclusivamente, linguas, variedades e variantes, os psicólogos sociais avaliam não só línguas diferentes, mas reações de falantes a pessoas, grupos e questões sociais.

O trabalho com a percepção parece novo, quando se observa, por exemplo, as pesquisas de produção em sociolinguística. No entanto, a definição parece emergir com o crescente refinamento das práticas metodológicas no campo da sociolinguística e, mais do que isso, com vistas a correlacionar significados sociais a variantes linguísticas. Uma longa tradição de pesquisas em atitudes linguísticas e a psicologia social da linguagem já demonstrou a influência da linguagem, da variedade linguística e das sugestões paralinguísticas na percepção social - para uma visão mais precisa dessa visão geral, ver Giles e Billings (2004).

Conclui-se, portanto, que os três dominios são de fato complementares. Não há sequer uma especificação metodológica que leve à separação dos conceitos ou à tentativa, por parte de alguma pesquisa, de separá-los. A técnica de matched, por exemplo, originalmente construída no seio da Psicologia Social, tem sido usada em todos os três tipos de estudos: percepção, avaliação e atitudes. Além disso, o que se tem observado é o aperfeiçoamento da presente técnica e também o agregar de novos métodos a depender do objetivo da pesquisa.

\section{SOCIOlinguistic PERCePtions, SUBJECTIVE EVAlUATIONS AND LINGUISTIC ATtitudes: THREE COMPLEMENTARY DOMAINS}

Abstract: This article aims to present a review of literature and a theoreticalmethodological discussion of some of the main studies of sociolinguistic perceptions, subjective evaluations and linguistic attitudes. For this, we review the work of Preston (1986), Gibson (1991), Campbell-Kibler (2006), Podesva (2007), 
Levon (2007), Eckert (2012), Oushiro (2015), Weinreich, Labov e Herzog (1968), Labov (2010), Lambert et al (1960), Oppenheim (1966), Moreno Fernández (1998), Garrett, Coupland and Williams, (2003), Garrett (2010), among others. In addition, it aims to establish the points of contact between the three strands, justifying why they become complementary domains for sociolinguistic studies.

Keywords: Sociolinguistic perceptions. Subjective evaluations. Linguistic attitudes.

\section{REFERÊNCIAS}

AGUILERA, V. de A. Crenças e atitudes linguísticas: o que dizem os falantes das capitais brasileiras. Estudos Linguísticos, São Paulo, v. 2, n. 37, p. 105-112, 2008. AYZEN, I.; FISHBEIN, M. Understanding attitudes and predicting social behavior. Englewood Cliffs: Prentice-Hall, 1980.

BARCELOS, A. M. F. Crenças sobre ensino e aprendizagem de línguas: reflexões de uma década de pesquisa no Brasil. In: ALVAREZ, M. L. O.; SILVA, K. A. (org.). Lingüística Aplicada: múltiplos olhares. Campinas: Pontes, 2007. p. 27-69.

BAUMANN, O.; BELIN, P. Perceptual scaling of voice identity: common dimensions for different vowels and speakers. Psychol Res., v. 74, n. 1, p. 110-120, 2010. BELL, A. Language style as audience design. Language in Society, v. 13, n. 2, p. 145-204, jun. 1984.

BERGAMASCHI, M. C. Z. Bilinguismo de dialeto italiano-português: atitudes linguísticas. 2006. 154 f. Dissertação (Mestrado em Letras e Cultura Regional)Universidade de Caxias do Sul, Caxias do Sul, 2006.

BISINOTO, L. S. J. Atitudes sociolinguísticas: efeitos do processo migratório. Campinas: Pontes, 2007.

BOERSMA, P.; WEENINK, D. Praat: doing phonetics by computer. Evaluation al reaction stop spoken languages. 2014. Disponivel em: http://www.fon.hum.uva. nl/praat/. Acesso em: 4 abr. 2019.

BRECKLER, S. Empirical validation of affect, behaviour and cognition as distinct components of attitudes. Journal of Personality Social Psychology, v. 47, n. 6, p. 1191-1205, Jan. 1984.

BYBEE, J. Phonology and language use. Cambridge: Cambridge University Press, 2001.

CAMPBELL-KIBLER, K. Listener perceptions of sociolinguistic variables: the case of (ing). 2006. 282 f. Tese (Doutorado em Linguística)-Stanford University, Stanford, 2006.

CAMPBELL-KIBLER, K. The nature of sociolinguistic perception. Language Variation and Change, v. 21, n. 1, p. 135-56, abr. 2009.

CARDOSO, D. P. Atitudes linguísticas e avaliações subjetivas de alguns dialetos brasileiros. São Paulo: Blucher, 2015.

CLOPPER, C. G; PISONI, D. B. Perception of dialect variation. In: PISONI, D. B.; REMEZ, R. E. (ed.). The handbook of speech perception. Oxford: Blackwell Publishing, 2005. p. 313-337. 
CYRANKA, L. F. Atitudes linguísticas de escolas públicas de Juiz de Fora. 2007. Tese (Doutorado em Linguística)-Universidade Federal Fluminense, Niterói, 2007.

DRAGER, K. Sociophonetic variation in speech perception. Language and Linguistics Compass, v. 4, n. 7, p. 473-480, 2010.

ECKERT, P. Linguistic variation as social practice. Oxford: Blackwell, 2000.

ECKERT, P. Three waves of variation study: the emergence of meaning in the study of variation. Annual Review of Anthropology, v. 41, p. 87-100, 2012.

EDWARDS, J. Refining our understanding of language attitudes. Journal of Language and Social Psychology, v. 18, n. 1, p. 101-110, 1999.

FISKE, S. T.; NEUBERG, S. L. A continuum of impression formation, from category-based to individuating processes: influences of information and motivation on attention and interpretation. Advances in Experimental Social Psychology, v. 23, p. 1-74, dez. 1990.

FOULKES, P.; SCOBBIE, J. M.; WATT, D. Sociophonetics. In: HARDCASTLE, W.; LAVER, J.; GIBBON, F. (ed.). Handbook of phonetic sciences. Oxford: Blackwell, 2010. p. 703-754.

FOULKES, P.; KHATTAB, G.; YEGER-DROR, M. Sound judgments: perception of indexical features in childrens speech. In: PRESTON, D. R.; NIEDZIELSKI, N. (org.). A reader in sociophonetics. New York, 2010. (Trends in Linguistic. Studies and monographs, 219).

FREIRE, J. B. Variação, estilo, atitude e percepção linguística: o caso das laterais/K/e/1/no falar paraibano. 213 f. 2016. Tese (Doutorado em Linguística)-Universidade Federal da Paraíba, João Pessoa, 2016.

FREITAG, R. M. K.; SANTOS, A. de O. Percepção e atitudes linguísticas em relação às africadas pós-alveolares em Sergipe. In: LOPES, N. da S.; ARAÚJO, S. S. de F.; FREITAG, R. M. K. (org.). A fala nordestina: entre a sociolinguística e a dialetologia. São Paulo: Blucher, 2016. p. 109-122.

GARCIA, B. L. Identidade social e atitude linguística: um estudo da fala de Bonfim Paulista. 157 f. 2018. Dissertação (Mestrado em Linguística e Língua Portuguesa)-Universidade Estadual Paulista "Júlio de Mesquita Filho", Araraquara, 2018.

GARRETT, P. Attitudes to language. Cambridge: Cambridge University Press, 2010.

GARRETT, P.; COUPLAND, N.; WILLIAMS, A. Investigating language attitudes. University of Wales Press: Cardiff, 2003.

GIBSON, E. J. How perception really develops: a view from outside the network, in an odyssey in learning and perception. Cambridge: MIT Press, 1991.

JEKOSCH, U. Voice and speech quality perception. Assessment and Evaluation. New York: Spring, 2005.

KAUFMANN, G. Atitudes na Sociolinguística: aspectos teóricos e metodológicos. In: MELLO, H.; ALTENHOFEN, C.; RASO, T. (org.). Os contatos linguísticos no Brasil. Belo Horizonte: Editora UFMG, 2011.

KOTHANDAPANI, V. Validation of feeling, belief, and intention to act as three components of attitude and their contribution to prediction of contraceptive behaviour. Journal of Personality Social Psychology, v. 19, p. 321-333, Oct. 1971. 
LABOV, W. The social stratification of English in New York City. Washington, DC: Center for Applied Linguistics, 1966.

LABOV, W. Padrões sociolinguísticos. São Paulo: Parábola, 2008 [1972].

LABOV, W. Principles of linguistic change. Oxford: Blackwell, 2010. Volume 3: Cognitive and cultural factors. 2010.

LAMBERT, W. E. et al. Evaluational reactions to spoken languages. The Journal of Abnormal and Social Psychology, American Psychological Association, v. 60, n. $1,1960$.

LAMBERT, W. E. A social psychology of bilingualism. Journal of Social Issues, Wiley Online Library, v. 23, n. 2, p. 91-109, 1967.

LAMBERT, W. W.; LAMBERT, W. E. Psicologia social. Rio de Janeiro: Zahar Editores, 1972. v. 3.

LEVON, E. Sexuality in context: variation and the sociolinguistic perception of identity. Language in Society, v. 36, p. 533-554, Oct. 2007.

LEVON, E.; FOX, S. Social salience and the sociolinguistic monitor: a case study of ING and TH-fronting in Britain. Journal of English Linguistics, v. 42, n. 3, p. 185-216, 2014.

MENDES, R. B. Gendered perceptions of noun agreement in Brazilian Portuguese. Revista Internacional de Linguística Iberoamericana, v. XVII, p. 93-108, 2014. MOLINA, J. R. G. Actitudes lingüisticas en una comunidad bilingüe y multilectal: área metropolitana de València. València: Publicacions de la Univerdad de València, 1998.

MORENO FERNÁNDEZ, F. Principios de sociolingüística y sociología del lenguaje. Barcelona: Editorial Ariel, 1998.

OUSHIRO, L. Identidade na pluralidade: avaliação, produção e percepção linguística na cidade de São Paulo. 2015. Tese (Doutorado em Linguística)-Universidade de São Paulo, São Paulo, 2015.

OPPENHEIM, A. N. Questionnaire design, interviewing and attitude measurement. New York: Basic Book. Inc., 1966.

PODESVA, R. J. Phonation type as a stylistic variable: the use of falsetto in constructing a persona. Journal of Sociolinguistics, v. 11, n. 4, p. 478-504, 2007. PRESTON, D. Five visions of America. Language in Society, v. 15, n. 2, p. 221-240, 1986.

PRESTON, D. Variation in language regard. In: GILLES, P.; SCHARLOTH, J.; ZEIGLER, E. (ed.). Empirische Evidenzen undthe oretische Passungen sprachlicher Variation. Frankfurt: Peter Lang, 2010. p. 7-27.

PRESTON, D. The power of language regard: discrimination, classification, comprehension and production. Dialectologia, v. II, special issue, p. 9-33, 2011.

REZENDE, T. F. Atitudes sociolinguisticas e posturas politicas balizadoras das práticas escritas nas aulas de lingua portuguesa. Projeto de pesquisa, PRPPG/ UFG (2014-2017), 2014.

RUSHER, J. B.; HAMMER, E. D. The development of shared stereotypic impressions in conversation: an emerging model, methods, and extensions to crossgroup settings. Journal of Language and Social Psychology, v. 25, n. 3, p. 221-243, 2006. 
ROSENBERG, J.; HOVLAND, C. Cognitive, affective, and behavioural components of attitudes. In: ROSENBERG, J. et al. (org.). Attitudes organisation and change: an analysis of consistency among attitude and components. New Haven: Yale University Press, 1960.

ROSENBLUM, L. D. Primacy of multimodal speech perception. In: PISONI, D. B.; REMEZ, R. E. (ed.). The handbook of speech perception. Oxford: Blackwell Publishing, 2008. p. 51-78.

RYLES, E. B.; GILES, H.; SEBASTIAN, R. J. An integrative perspective for the study of attitudes toward language variation. In: RYAN, E. B.; GILES, H. Attitudes towards language variation: social and applied contexts. Studies in Second Language Acquisition, London, v. 7, n. 1, p. 117-119, Feb. 1985.

SANTOS, E. D. Certo ou errado? Atitudes e crenças no ensino de língua portuguesa. Rio de Janeiro: Graphia, 1996.

SARNOFF, I. Social attitudes and the resolution of motivational conflict. In: JAHODA, M.; WARREN, N. (org.). Attitudes. Harmondsworth: Penguin, 1970. p. 279-284.

SORIANO, L. G. M. Percepções sociofonéticas do (-r) em São Paulo. 2016. Dissertação (Mestrado em Linguística)-Universidade de São Paulo, São Paulo, 2016.

THOMAS, E. R. Sociopohnetic applications of speech perception experiments. American Speech, v. 77, n. 2, p. 115-147, Summer 2002.

THOMASON, S. G. Language contact: an introduction. Georgetown: Georgetown University Press, 2001.

WEINREICH, U.; LABOV, W.; HERZOG, M. Empirical foundations for a theory of language change. In: LEHMANN, W. P.; MALKIEL, Y. (ed.). Directions for historical linguistics. Austin: University of Texas Press, 1968. p. 95-195.

WILLIAMS, F. Some research notes on dialect attitudes and stereotypes. In: FASOLD, R. W. (ed.) Variation in the form and use of language: a sociolinguistics reader. Washington: Georgetown University Press, 1973. p. 354-369.

WOLFRAM, W.; SCHILlING, N. American English. Oxford: Blackwell, 1998.

Recebido em 15 de fevereiro de 2018.

Aprovado em 18 de outubro de 2018. 